\title{
APPLICATION OF DEA METHOD TO INTERMODAL CONTAINER TRANSPORT
}

\author{
Aleksandar Radonjić ${ }^{1}$, Danijela Pjevčević ${ }^{2}$, Zlatko Hrle ${ }^{3}$, Vladeta Čolić ${ }^{4}$ \\ Faculty of Transport and Traffic Engineering, University of Belgrade, Vojvode Stepe 305, \\ 11000 Belgrade, Serbia \\ E-mails: ${ }^{1}$ a.radonjic@sf.bg.ac.rs (corresponding author); ${ }^{2}$ danijela@sf.bg.ac.rs; \\ ${ }^{3}$ hrle@sf.bg.ac.rs; ${ }^{4}$ v.colic@sf.bg.ac.rs
}

Received 18 July 2010; accepted 24 July 2011

\begin{abstract}
In order to make better assessment of intermodal container transportation, the authors have analyzed DEA (Data Envelopment Analysis) method in deciding the most favorable container line from Serbian ports to the near East ports. To allow for applications to a wide variety of activities, term organization unit (Decision Making Unit - DMU) refers to container line. DEA Method has been used to give the estimation of efficiency of operations in organization units. Organization units are container lines in which containers are loaded with mineral water in bottles. The main points in transportation net are factories of mineral water (Knjaz Milos Arandjelovac and Minaqua Novi Sad), Serbian ports ( the Port of Belgrade, the Port of Danube Pancevo and the Port of Prahovo) and nine Mediterranean ports in the near East area. Amount of mineral water that is dispatching from factories to Serbian ports is equal to amount that can be loaded to one container. Having containerized in Serbian ports mineral water is reloaded to the river-sea ships with unified dimensions, so the ships are continuing to travel to the near East ports. The near East ports are the ending points. Input variables in DEA problem are transportation costs and strategy resistance factor in function of container line. Time traveling of one container is in a function of container line and transportation capabilities of container lines are output variables. Transportation costs are counted on the base of integer programming method and Dijkstra algorithm.
\end{abstract}

Keywords: data envelopment analysis (DEA), decision making unit (DMU), TEU, container, mineral water, river-sea ship.

\section{Introduction}

This work investigates the introduction of DEA method, in an effort to measure efficiency of transportation of mineral water in containers from factories in Serbia to the near East ports. Transportation as a process is described by a criterion costs of transportation (Lingaitienè 2008), therefore, all means of transport are integrated into one single system.

For the planning case, a pilot network is made of 2 mineral water factories, 3 river ports on the river Danube in Serbia and 9 near east ports including 19 sea links and 6 road links. Formulation of the problem allows exploration of problems for higher dimensions with respect to cost and utilization of transportation means.

Mineral water transportation from factories in Arandjelovac and Novi Sad is performed by means of road transport mode to ports on the Serbian section of the river Danube. Containerizing mineral water is loaded on the river-sea ships at the Serbian ports contain- ers and travels to destination ports at the near East. The target of this paper is the establishment of traffic lines and then investigation of efficiency of every line with DEA method.

The capacity of river-sea ship is 96 containers. Ship travels from the port of Izmail to the port of Regensburg 14 days (up the river), and from the port of Regensburg to the port of Izmail 9 days (down the river) according to the Ukrainian Danube Shipping Company (2010).

Efficiency of every traffic line obtained with DEA method is the function of the road transport and the river transport because the changes in the traffic lines of the entire network are appearing with the change of a number of river ports as the solution and not appearing with the number of sea ports as the solution as well. Sea ports remain the same for all solutions. In the problem of dispatching the ships from Izmail to near East ports it is used Dijkstra algorithm. With Dijkstra algorithm solutions are always optimal. Mineral water factories are the same in all the alternatives of solutions, but the val- 
ues of distances from mineral water factories to Serbian ports are varying with various types of roads appearing in the alternatives, and that is the reason why the road transportation is presented in the final solution.

The fundamental approach of the paper is the efficiency in operations and in making better economic effects (outputs). The efficiency in the paper can be defined as the capability of achieving desired objectives with the minimal utilization of resources. The attention is on efficient use of different transport modes as well as on various modern means in the interface of transport systems (Baublys 2009).

In the last couple of years, for the analysis of the cognate entities with common inputs and outputs and for an assessment of relative efficiency of entities it is developed Data Envelopment Analysis (DEA) method. Data Envelopment Analysis method has been developed by Charnes et al. (1978). The reason why they have developed this method is the efficiency measure of organizational units.

Organizational unit and the efficiency of the organizational unit should be evaluated with the consideration of heterogeneous inputs and outputs. The name of the organizational unit in DEA term is Decision Making Unit - DMU. In the next lines terms unity, entity and DMU will be used for the same sort of units.

Charnes et al. (1978) in their originating study, described DEA as a mathematical programming model applied to observational data that provides a new way of obtaining empirical estimates of relations - such as the production functions and/or efficient production possibility surfaces - that are cornerstones of modern economics.

Creators of DEA method (Charnes et al. 1978) suggested nonparametric approach for evaluating efficiency. They minimized multiple inputs and outputs on one 'virtual' input and output on the base of weight factors. The problem of weight assignment they solved in a way of letting every unit to determine own weight factor with the aim to maximize its own efficiency. The constraint is on the value of weight factors that have to be positive. Another constraint is that ratio between virtual output and virtual input cannot be higher than 1 . This problem is defined as a formulation of linear programming (Vanderbei 2007) titled 'CCR ratio model'.

Charnes et al. (1978) suggested new method for the estimation of production frontiers. Starting with the efficiency criteria in case when it is producing one output on the base of more inputs, Charnes et al. (1978) suggested optimization method of mathematic programming for evaluating the performance of technical efficiency of entity with more then one input.

Roll and Hayuth (1993) were one of the first to apply DEA for the evaluation of seaport efficiency. In their study, port efficiency was measured in terms of throughput, level of service, port users' satisfaction and frequency of calls made by ocean carriers. Three inputs were given which are as follows: size of labor force, capital investment and cargo uniformity. Although Roll and Hayuth (1993) considered multiple outputs, they did not use actual data to measure the port efficiency. Also, their study was limited to a single-period, crosssectional analysis.

Martinez-Budria et al. (1999) extended the work of Roll and Hayuth (1993) to include multiple periods (1993-1997) and actual data involving 26 Spanish ports. In applying DEA for port performance evaluation, they took into account three inputs: labor expenditure, depreciation charges and miscellaneous expenditure, while using two outputs: revenue through port rentals and the total amount of cargo moved through docks.

As such, Martinez-Budria et al. (1999) focused on the financial performance of ports. Similarly, Tongzon (2001) identified factors influencing port efficiency and used six of those factors as inputs: the number of cranes, the number of container berths, the number of tugs, size of the terminal areas, length of delay and size of labor force in measuring the efficiency of Australian ports. The outputs of his DEA model include cargo throughput and ship working rate. The DEA model developed by Tongzon (2001) was also confined to a single period.

\section{Problem Description}

The problem consists of three parts representing different mode of transport.

The first part of the problem is the transportation problem of linear programming (LP). Mineral water factories in Arandjelovac and Novi Sad are production centers where the mineral water is packed in bottles, loaded to trucks and dispatched to the river ports. Factories are considered as origin points from which freight transportation is organized. Destination points in the first part of the problem are river ports in Serbia and they are ports of Belgrade, the Danube port Pancevo and the port of Prahovo. All three ports have container terminals where mineral water is containerized. The total amount of freight that should be carried from mineral water factories to river ports is equal to annual demand at the near East ports. The demand at near East ports is equal to the sum of all container terminal throughput, or port throughput. If the demand exceeds the sum of the port throughput, it will be considered that the port authorities rent the needed aids. Freight transport is characterized by transportation cost which depends on the distance of the optimal route between origin and destination nodes (points). Transportation cost is in dollars per TEU (twenty-foot equivalent unit) units. The amount of mineral water in one truck is equal to the capacity of one container and it can be said that the capacity of one truck is equal to the capacity of one container. Containers are loaded to the river-sea ships. The optimal plan of traffic flow is the plan that involves minimal costs from origin points to destination points.

The second part of the problem is the problem of container transportation from the Danube ports in Serbia to the port of Izmail. This is the transportation problem on the river Danube. The only costs involved in this problem are the transportation costs. They are computed upon the number of days that ship spends in 
a trip from Serbian river ports to the port of Izmail. The origin points in this problem are river ports in Serbia while the destination point is the port of Izmail.

The third part of the problem is the problem of container transport from the port of Izmail to the near east ports. The near East ports are Trabzon (Turkey), Izmir (Turkey), Piraeus (Greece), Limassol (Cyprus), Iskenderun (Turkey), Latakia (Syria), Tripoli (Lebanon), Alexandria (Egypt). This problem has two parts. In the first part the shortest paths from the port of Izmail to the near East ports are defined by the Dijkstra's algorithm (Teodorović 1996) and the ship routes are defined too. In the second part the optimal number of ships per ship line or the fleet size is determined per one year. Along with determination of number of ships and ship routes, the ship costs are specified as the transportation costs. Transportation costs are computed on the base of the Integer programming (IP) formulation.

The annual number of containers is presumed and this number has to be equal to the near East port demands. Total demand or demand at the near East ports is divided into the number of countries involved in the transportation network which makes some value. If the country has one port this value is demand at its port, otherwise the value is divided with the number of ports in one considered country and new obtained value is demand at one port among the more of one country. The costs of loading and unloading containers are not considered because they cannot affect the final solutions as they are equal to all three Serbian ports.

The solution to this phase of the problem is to determine optimal transportation lines in road mode of transport as well as in water transport on the transportation network consisting of origin points (Arandjelovac and Novi Sad), transit points (the port of Belgrade, The Danube port Pancevo, the port of Prahovo and port of Izmail) and destination points (near East ports). Various alternative solutions are obtained from the method of combining the optimal lines of transportation.

\section{Mathematical Formulation of Intermodal Transportation}

Mathematical formulation of the transportation problem of linear programming means that sources and destinations have to be defined. The sources are mineral water factories and their term is ' $s$ ' while destinations are river ports in Serbia and they are signed with ' $d$. Constraints are as follows:

$$
\begin{aligned}
& \sum_{i=1}^{m} s_{i}=\sum_{j=1}^{n} d ; \\
& \sum_{j=1}^{n} x_{i j}=s_{i} ; \\
& \sum_{i=1}^{m} x_{i j}=d_{j},
\end{aligned}
$$

where: $x_{i j}$ - the amount of mineral water from the source $i$ to the destination $j$.

If $C_{T i j}$ are the transportation costs from the source $i$ to destination $j$ then the objective function $F_{1}$ is:

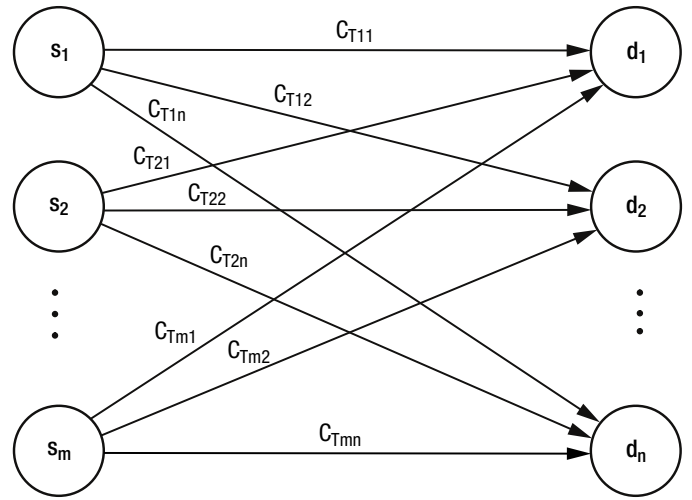

Fig. 1. Graphic formulation of transportation problem

$$
\min \rightarrow F_{1}=\sum_{i=1}^{m} \sum_{j=1}^{n} C_{T i j} \cdot x_{i j} \quad \text { (\$). }
$$

Transportation problem is shown in Fig. 1.

Transportation costs $C_{T i j}$ are computed as follows:

$$
C_{T i j}=c_{a} \cdot \sum_{z=1}^{r} d_{T}+c_{F} \cdot \sum_{z=1}^{r} c_{f} \cdot d_{T} \quad(\$ / \mathrm{TEU}),
$$

where: $c_{F}$ - cost of fuel per liter $(\$ / 1) ; d_{T}$ - traveled distance $(\mathrm{km}) ; c_{a}$ - additional consumption per kilometer $(\$ / \mathrm{km}) ; c_{f}$ - fuel consumption per 100 kilometers in liters $(1 / 100 \mathrm{~km}) ; z$ - various types of roads (traveled distance consists of various road types - highway, main road, link road, regional road and urban streets).

In the second part of the problem transportation costs consist of propulsion costs $\left(C_{p}\right)$ divided on ship fuel costs $\left(C_{F S}\right)$, lubricant costs $\left(C_{l u}\right)$, costs of additional materials $\left(C_{a m}\right)$ and costs of additional material for auxiliary units $\left(C_{\text {amau }}\right)$.

Fuel costs are as follows according to Čolić et al. (1988):

$$
C_{F S}=w_{f} \cdot N_{\text {inst }} \cdot t_{v p} \cdot c_{F} \cdot \psi(\$ / \text { ship }),
$$

where: $w_{f}-$ specific fuel consumption $(1 / \mathrm{kWh}) ; N_{\text {inst }}-$ main engines output $(\mathrm{kW}) ; t_{v p}$ - time of traveling $(\mathrm{h})$; $\Psi$ - utility factor of main engines.

Lubricant costs are as follows according to Čolić et al. (1988):

$$
C_{l u}=w_{l u} \cdot N_{i n s t} \cdot t_{p v} \cdot c_{l u}(\$ / \text { ship }),
$$

where: $w_{l u}$ - specific consumption of lubricant $(1 / \mathrm{kWh})$; $c_{l u}$ - lubricant cost per liter $(\$ / 1)$.

Costs of additional materials $\left(C_{a m}\right)$ are $3 \%$ of sum of $C_{F S}$ and $C_{l}$ while costs of additional material for auxiliary units $\left(C_{a m a u}\right)$ are $10 \%$ of sum of $C_{F S}, C_{l u}$ and $C_{a m}$. Transportation costs are as follows according to Čolić et al. (1988):

$$
C_{p}=C_{F S}+C_{l u}+C_{a m}+C_{a m a u} \text { (\$/ship). }
$$

Problem of ship assignment is defined on the transportation network consisted of node set or ports and link set or links between ports (Fig. 2). Supposing that $W_{k l}$ is the amount of freight that is transported from 
node $k$ to node $l$, and supposing that: $n_{k l}$ - number of ships from port $k$ to port $l$ per year; $n_{\max }-$ maximum number of ships per year; $t_{v p k l}$ - travel time between port $k$ and port $l$ in days; $C_{p k l}$ - transportation costs of one ship between port $k$ and port $l$ per day (\$/day); $Q$ - ship capacity in TEU units (constant for all ships); $D_{k}$ - demand at port $k$ in TEU units; $S_{k}$ - supply at port $k$ in TEU units.

The objective function $F_{2}$ according to Petrić (1989) is:

$$
\min \rightarrow F_{2}=\sum_{k \in U} \sum_{l \in N} C_{p k l} \cdot n_{k l} \cdot 24(\$),
$$

where: $U$ - port precedence set - dispatching ports $(U \subset N$ and only pairs from Dijkstra algorithm are valid); $N$ - set of all near east ports on the transportation network, subject to:

$$
\sum_{l \in U} W_{l k}-\sum_{t \in B} W_{k t}+S_{k}-D_{k}=0,
$$

where: $B$ - set of ports that are on the shortest path from the port $k$ to the port $l(B \subset N)$.

$$
\left(n_{k l}-1\right) \cdot Q \leq W_{k l} \leq n_{k l} \cdot Q
$$

lower and upper bound constraint for $W_{k l}$;

$$
0 \leq n_{k l} \leq n_{\max }
$$

lower and upper bound constraint for $n_{k l}$;

$$
W_{k l} \geq 0
$$

non-negativity constraints for $W_{k l}$;

$$
n_{k l} \geq 0
$$

non-negativity constraints for $n_{k l}$;

$$
n_{k l}=[0,1,2,3, \ldots]
$$

integer $n_{k l}$.
The sum objective function $F$ is:

$$
F=F_{1}+\sum_{j=1}^{n} C_{p j} \cdot n_{j}+F_{2}(\$),
$$

where: $n_{j}$ - number of ships that travel from Serbian port $j$; $C_{p j}$ - transportation costs for one ship from Serbian port $j$ to the port of Izmail.

Number of ships per year $n_{\text {max }}$ is derived from expressions (10) and (11), but it can be higher then sum of $n_{j}$ and the value of difference between $n_{\max }$ and sum of $n_{j}$ is always added to the number of ships that travel from port of Prahovo to port of Izmail.

\section{Defining Solution Alternatives}

Transport of mineral water begins at the factories in Arandjelovac and Novi Sad. The entire supply at those factories is supposed to be equal to the demand at the near East ports. If the solution is to be feasible, it will be presumed that the port throughput is at the level needed for the load of all containers in the problem. Supply at the factories is divided in a fashion that $50 \%$ goes to supply at Arandjelovac and that 50\% goes to supply at Novi Sad. This means that supply at Arandjelovac is equal to 7500 TEU units, but also is equal to 7500 TEU units at Novi Sad too.

Alternatives are determined not only as on the base of number of ports that take part in the entire transport of container, but also as a function of their combination in one alternative if their number is equal to more then one alternative. It is presumed that the Port of Belgrade always has greater throughput then the Danube Port Pancevo and the Port of Prahovo, while the Danube Port Pancevo has greater throughput the Port of Prahovo.

The first alternative $\left(M_{1}\right)$ includes all three ports. It is supposed that the entire demand per year is 15000 TEU units. 7000 TEU units go to the Port of Belgrade, 5000 TEU units go to the Danube Port Pance-

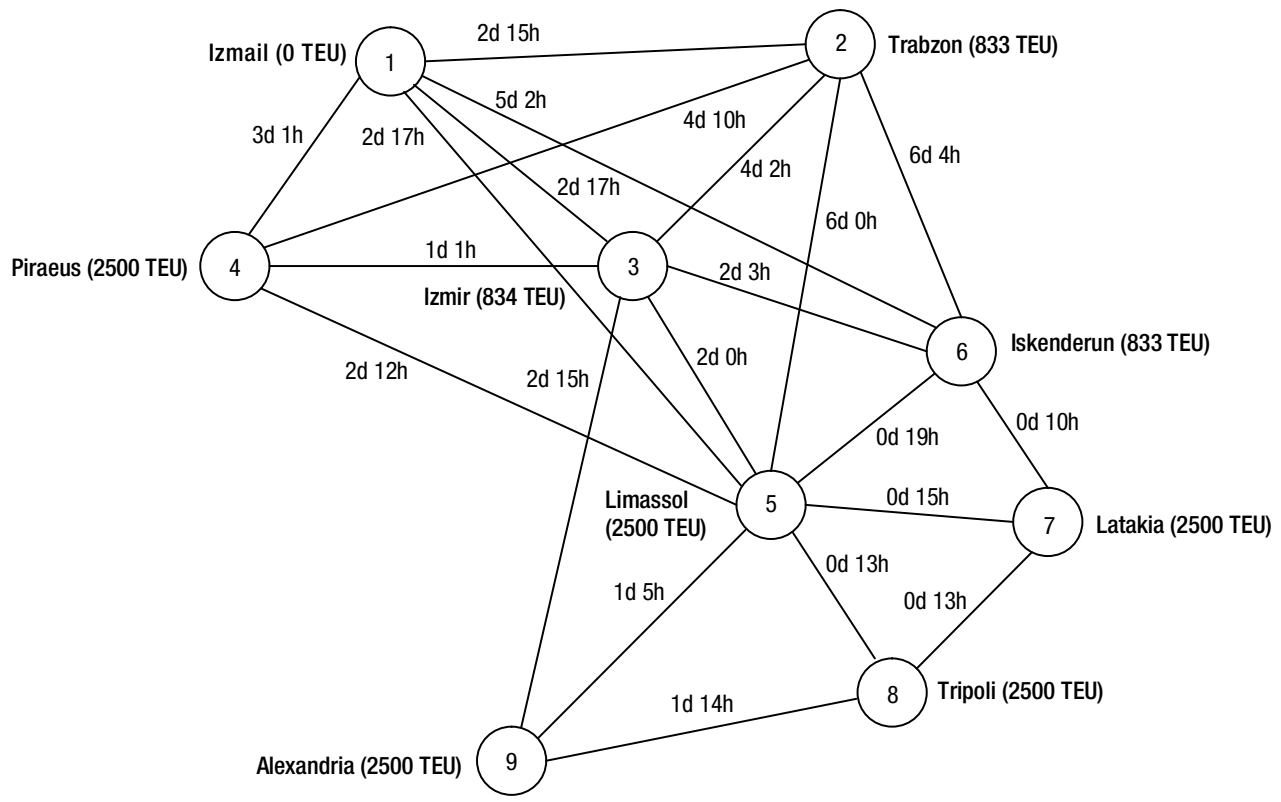

Fig. 2. Transport network for the near East ports 
vo and 3000 TEU units are reserved for the Port of Prahovo.

In the second alternative $\left(M_{2}\right)$ it is used only the Port of Prahovo. It means that all 15000 TEU units goes to this port.

The third alternative $\left(M_{3}\right)$ uses the Port of Belgrade and the Danube Port Pancevo. The Port of Belgrade reloads 9000 TEU units while the Danube Port Pancevo reloads 6000 TEU units.

The Port of Belgrade and the Danube Port Pancevo are the ports that take part in the fourth alternative $\left(M_{4}\right)$. The port of Belgrade takes part with 11000 TEU units while the Danube Port Pancevo takes 4000 TEU units.

The fifth alternative $\left(M_{5}\right)$ comprises the Danube Port of Pancevo and the Port of Prahovo. The Danube Port Pancevo operates with 11000 TEU units while the Port of Prahovo operates with 4000 TEU units.

Demand at the near East ports is divided on the number of ports in one country. This means that the number of total demand of 15000 TEU units per year is divided with the number of countries the near East ports are located in and then virtual number of demand at one country is divided with the number of the cities or ports that participate in the transportation network.

\section{Application of DEA Method}

Efficiency measure obtained by DEA method is a relative measure because it depends on which and how many entities are involved in procedure, but also depends on number and structure of input and output data. This measure does not depend on measure units of data except that every input or output has to be given in the same measure for all entities.

It is suggested that all inputs and outputs for the units (whose efficiency is evaluating) have to be determined (Charnes et al. 1978). DEA gives the weights of inputs and outputs leading to the calculated efficiency. The unit is efficient if the efficiency is equal to 1 and inefficient if it is less than 1. It is free to evaluate weight coefficient for any DMU in the most acceptable way for it. In that way, it is possible to maximize DMU's efficiency but also is possible to obtain other efficient DMUs.

An input-oriented measure quantifies the input reduction, which is necessary for a DMU to become efficient, holding the output constant. Similarly, an output-oriented measure quantifies the necessary output expansion, holding the input constant. A non-oriented measure quantifies the improvements when both inputs and outputs can be modified simultaneously. DEA suggests the creation of virtual unit B' for the inefficient unit B. B' lies on the efficient frontier and is the best practice for unit $B$, if it aims to be efficient. The outputs and inputs of such a virtual unit are linear combinations of corresponding outputs and inputs of all other units. Thus, DEA gives inputs/outputs targets for inefficient units - a benchmarks. The benchmark represents the peer group for the inefficient DMU.

DEA suggests the benchmark for each inefficient DMU at the level of its individual mix of inputs and outputs.
As a most important performance of the DEA method many authors indicate 'objectivity of the method' because there is no 'subjective judgment' for the decision maker. But sometimes weights determined by DEA analysis can be in the opposite side with the previous standpoints.

The DEA model is mathematically expressed as:

$$
\left(^{\star}\right) \max \left(E f f_{m}=\frac{\sum_{k=1}^{s} u_{k} \cdot y_{k m}}{\sum_{i=1}^{t} v_{i} \cdot x_{i m}}\right)
$$

subject to:

$$
\begin{aligned}
& \frac{\sum_{k=1}^{s} u_{k} \cdot y_{k i}}{\sum_{i=1}^{t} v_{i} \cdot x_{i m}} \geq 1 ; \\
& u_{k}, v_{i} \geq 0 .
\end{aligned}
$$

The DEA model is formulated as optimization model maximizing the efficiency of DMU, subject to the efficiency of all DMUs being $\leq 1$.

DEA-LP $\left(^{*}\right)$ :

$$
\text { (**) } \max \left(\sum_{k=1}^{s} u_{k} \cdot y_{k m}\right)
$$

subject to:

$$
\begin{aligned}
& \sum_{i=1}^{t} v_{i} \cdot x_{i m}=b ; \\
& \sum_{k=1}^{s} u_{k} \cdot y_{k m}-\sum_{i=1}^{t} v_{i} \cdot x_{i m} \leq 0, \forall j ; \\
& u_{k}, v_{i} \geq 0 \text { or } \varepsilon,
\end{aligned}
$$

where: $y_{k m}$-amount of output $k$ produced by DMU $j$; $u_{k}$ - the weight given to output $k ; x_{i m}$ - amount of input $i$ used by DMU $j ; v_{i}$ - the weight given to input $i$; $b$ - constant; $E_{f f m}$ - efficiency of $m$-th DMU; $\varepsilon$ - a small positive number could be introduced in order to avoid any input or output being totally ignored in determining the efficiency.

The efficiency of the target unit ( $m$ unit) is obtained from the $\left(^{* *}\right)$ model. Obtained values of weights $(u, v)$ are the best from the viewpoint of $m$ unit. Weights made for any of two units can be different because the objective functions are different.

The first phase in efficiency analysis is the selection of relevant output and input criteria. Those criteria will be inputs for evaluating suggested transport organization.

Every alternative has more then one criterion. Considered criteria in CCR DEA model are as follows:

- the sum of transportation costs;

- time travel utilization;

- transportation work;

- strategy resistance factor. 
The sum of transportation costs comprises all transportation costs that appear in all mode of transport. These costs are not the only ones that exist in this problem, but their change implicates the greatest changes in solution.

Time travel of the ship is defined as a sum of times ship travels with the containers and empty.

Transportation work can be determined with a help of empirical, analytical, experimental and combined methods. Empirical methods are not applicable in the river transport and traffic. Analytical methods are based on mathematical models and logical relationships. They will be base for computing transportation work. Experimental methods consist of simulation models and they are the most adequate methods.

Transportation work can be determined in three ways:

- with a ship operating characteristics and parameters in the recent period of time;

- with a ship traffic;

- with a help of ship schedule chart for the various type of ships.

One important yardstick for choosing efficient strategies, however, is human behavioral resistance within the organization. One should often be aware of employees' resistance and their influence before making new decisions; otherwise the chosen strategy, though well intentioned, may not be efficient in the long-term.

Milani et al. (2006) defined human behavioral resistance as a natural response to a change because a change normally involves going from known to unknown. If one focuses only on the technical elements of these changes, without taking into account the equally important human behavioral resistance element, it can crucially undermine the organizational efficiency. On the other hand, since each individual and his/her perception of resistance is normally different from others, it would be desirable to combine individual behavioral resistances into an overall factor representing the resistance of a team, department, and eventually the whole organization.

Once an overall resistance for different strategies is defined, it can be included as a new criterion (strategy resistance factor) next to other technical criteria (Milani et al. 2006).

Values of mentioned criteria and efficiency of DMU are given in Table.

The sum of transportation costs and strategy resistance factor are used as an input values. Time travel utilization and transportation work criteria are output variables.

Results show the high efficiency of all suggested alternatives. Efficiency of DMU2, DMU3 and DMU5 is equal to 1 and those units are considered as efficient and they form the limit in efficiency. The lowest obtained efficiency is for DMU1 and it is 0.982. It means that if DMU1 is going to be efficient (value 1) inputs for this unit should be decreased in $1.8 \%$ of the value.
Table. Efficiency of DMUs

\begin{tabular}{|c|c|c|c|c|c|}
\hline  & 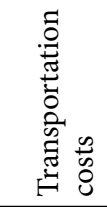 & 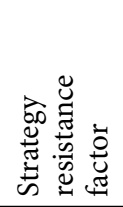 & 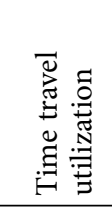 & 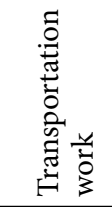 & 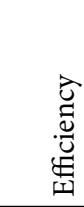 \\
\hline DMU1 & 8.115 & 0.5 & 0.392 & 17.657 & 0.982 \\
\hline DMU2 & 8.041 & 0.3 & 0.394 & 17.115 & 1.000 \\
\hline DMU3 & 7.924 & 0.6 & 0.391 & 18.094 & 1.000 \\
\hline DMU4 & 8.126 & 0.2 & 0.392 & 17.485 & 0.999 \\
\hline DMU5 & 8.144 & 0.2 & 0.393 & 17.544 & 1.000 \\
\hline
\end{tabular}

\section{Conclusions}

1. This paper has the target to show that DEA method is applicable for suggested transport of mineral water from Serbian factories to the near East ports.

2. Five alternatives of solution are analyzed on the base of two input and two output criteria that are directly the result of the suggested organization of transport.

3. As a result, efficiency equal to value 1 is obtained for three DMU2, DMU3 and DMU5. The value of efficiency index for other two units is very high but still not equal to 1 , and that is why those two units are not efficient.

4. Although DEA method is not ranking method (efficiency measure that gives is the relative measure), many authors used it for its practical reason. DMU or groups of units are chosen on the base of efficiency index.

5. CCR model, used in this paper, assigns efficiency index 1 and this is the reason why the ranking of units is useless. Further way of investigation would be headed on the analysis of efficiency of alternatives using other DEA models and using different selection of input and output criteria.

\section{References}

Baublys, A. 2009. Models of freight transport system development, Transport 24(4): 283-287. doi:10.3846/1648-4142.2009.24.283-287

Charnes, A. A.; Cooper, W. W.; Rhodes, E. 1978. Measuring the efficiency of decision making units, European Journal of Operational Research 2(6): 429-444. doi:10.1016/0377-2217(78)90138-8

Čolić, V.; Radmilović, Z.; Hrle, Z. 1988. Idejni tehnološki projekat transporta sirovog-primarnog benzina za potrebe hip "Petrohemija" Pančevo [Technological project of gasoline transportation for the HIP Petrohemija Pancevo]. Belgrade: University of Belgrade. 150 p. (in Serbian).

Lingaitienè, O. 2008. A mathematical model of selecting transport facilities for multimodal freight transportation, Transport 23(1): 10-15. doi:10.3846/1648-4142.2008.23.10-15 
Martinez-Budria, E.; Diaz-Armas, R.; Navarro-Ibanez, M.; Ravelo-Mesa, T. 1999. A study of the efficiency of Spanish port authorities using data envelopment analysis, International Journal of Transport Economics = Rivista Internazionale de Economia dei Trasporti 26(2): 237-253.

Milani, A. S.; Shanian, A.; El-Lahham, C. 2006. Using different ELECTRE methods in strategic planning in the presence of human behavioral resistance, Journal of Applied Mathematics and Decision Sciences 2006: 1-19. doi:10.1155/JAMDS/2006/10936

Petrić, J. 1989. Operaciona istraživanja [Operational research]. Belgrade: Science Book (in Serbian).

Roll, Y.; Hayuth, Y. 1993. Port performance comparison applying data envelopment analysis (DEA), Maritime Policy Management 20(2): 153-161. doi:10.1080/03088839300000025

Teodorović, D. 1996. Transportne mreže [Transportation networks]. Belgrade: University of Belgrade (in Serbian).

Tongzon, J. 2001. Efficiency measurement of selected Australian and other international ports using data envelopment analysis, Transportation Research Part A: Policy and Practice 35(2): 107-122. doi:10.1016/S0965-8564(99)00049-X

Ukrainian Danube Shipping Company. 2010. Available from Internet: <http://oaoudp.com.ua/content/blogcategory/21/50/lang,english $>$.

Vanderbei, R. J. 2007. Linear Programming: Foundations and Extensions. 3rd edition. Springer. 484 p. 